\title{
Generics as reflecting conceptual knowledge
}

James A. Hampton

\section{CpenEdition}

\section{Journals}

Electronic version

URL: http://journals.openedition.org/rlv/2036

DOI: $10.4000 /$ rlv.2036

ISSN: 1958-9239

\section{Publisher}

Presses universitaires de Vincennes

\section{Printed version}

Date of publication: 1 September 2012

Number of pages: 9-24

ISBN: 978-2-84292-350-1

ISSN: 0986-6124

\section{Electronic reference}

James A. Hampton, «Generics as reflecting conceptual knowledge », Recherches linguistiques de Vincennes [Online], 41 | 2012, Online since 01 September 2014, connection on 30 April 2019. URL : http://journals.openedition.org/rlv/2036 ; DOI : 10.4000/rlv.2036 
Recherches linguistiques de Vincennes 41 - 2012 - p. 9-24

\author{
James A. HAMPTON \\ Psychology Department, City University London
}

GENERICS AS REFLECTING CONCEPTUAL KNOWLEDGE

\begin{abstract}
Generics are proposed to reflect the nature of the conceptual system, whose prototype structure and vague boundaries make an unreliable basis for traditional treatments of truth and logic. Conceptual representations contain information that is considered germane and relevant to an understanding and familiarity with that concept. Such information includes fundamental or ontological features as well as information about the common or typical form that exemplars of the concept may take, and any other information that it is important for someone to know. Examples from the psychological literature are used to illustrate the relation between generics and the reasoning fallacies that can arise from dependence on similarity-based concepts. To understand the logic of generics, we should therefore look to the processes by which information becomes attached to, and a part of, the representation of a concept.
\end{abstract}

\title{
KEYWORDS
}

Generics, concept, prototype, similarity, reasoning. 


\section{Knowledge and generics}

Generic statements describe a state of affairs that is "generally" true in some sense. One of the important uses that we make of generic statements is to communicate information about the world to other people. "Rain is good for crops" we say, or "People take holidays in August". In fact statements that we make about the world are most often generic statements. Although we may state them with confidence, and we may be taken to be telling the truth by our listeners, yet if interpreted as expressing a universal truth, then they may very likely be false. Some crops don't need too much rain. Some people avoid taking holidays in August.

This paper will argue that the knowledge of the world that we communicate to others in language depends on an informational structure that is constructed from individual concept representations. These representations themselves contain or point to information that is considered germane and relevant to an understanding and familiarity with that concept. Such information includes fundamental or ontological features, such as that water is $\mathrm{H}_{2} \mathrm{O}$ and a liquid, but also information about the common or typical form that exemplars of the concept may take (ice, steam, fog), and any other information that it is important for someone to know (water freezes at zero degrees Celsius). In this paper I will review evidence that our conceptual knowledge is largely composed of "generic" information, and that people are quite ready to accept statements even when those statements are contradicted by counterexamples. Surprisingly, even class membership statements can be shown to have this property.

In exploring the conceptual contents of people's minds, a method that psychologists have often used is the "feature listing" task. Hampton (1979) developed an elaborated version of this task, aimed at making explicit the conceptual content underlying the meaning of some familiar category names such as Fruits, Sports and Vehicles. Participants were interviewed and asked seven different questions aimed at eliciting generic properties of these concepts. For example, as well as asking people what properties or features made something a fruit or not a fruit, following Lakoff's idea of "hedges" (Lakoff, 1973), people were also asked to consider why something might only "loosely speaking" count as a fruit, or why something might be considered "technically speaking" a fruit. Participants were also asked to consider what properties might make particular exemplars typical or atypical members of the category (following Rosch, 1975). More streamlined feature elicitation methods have since been used in many studies, with extensive feature norms being published for Flemish Dutch by De Deyne et al. (2008), and for Canadian English by McRae et al. (2005). As an illustration, Table 1 shows the features that people generated for two of the categories investigated in Hampton (1979). 
Further work by Wu and Barsalou (2009) provided a detailed qualitative analysis of the information that people generate. They divided the descriptive properties generated into four main categories: taxonomic (for example mentioning superordinate categories), entity (parts and appearance, functions), situational (contexts of use and associated actions) and introspective (people's mental states when interacting with the concept, including emotional, evaluative judgments).

Looking through the features listed in Table 1 it would appear that a large majority of the properties generated in this fashion will provide the basis for generic sentences. "Furniture is found in the home" or "Fruit is sweet" are statements that have the classic properties of generics. People will judge them true, in spite of possible or real counterexamples, such as park benches, or lemons.

Table 1: Features generated for two of the categories in Hampton (1979), in decreasing order of production frequency

FURNITURE
Has a specific function, used by humans
Is found in buildings
Is made of wood
Is for sitting on or in
Is attractive
Is for comfort, convenience or satisfaction
Is found in the home
Is man-made, manufactured
Is for putting things on or in
Is not just decorative
Has legs

FRUIT
Is a plant, organic, vegetation
Is edible, is eaten
Contains seeds
Grows above ground, on bushes or trees
Is juicy, thirst quenching
Is brightly coloured
Is sweet
Has an outer layer of skin or peel
Is round
Is eaten as a dessert, snack or on its own
Is a protection for seeds

\section{FRUIT}

Is a plant, organic, vegetation

Is edible, is eaten

Contains seed

Grows above ground, on bushes or trees Is juicy, thirst quenching

brightly coloure

weet

Has an outer layer of skin or peel

Is round

Is a protection for seeds

As a first hypothesis, I want to propose that one source of generic statements results from a read-out from this conceptual/knowledge database, without concern for the degree to which statements are universally or even most commonly true. In this paper, I will review studies that demonstrate the degree to which this lack of concern for quantification is evidenced across a range of tasks. It appears that when discussing and describing their knowledge of things in the world, the main determinant of what is taken as true (or false) has to do with the relevance and usefulness of the information, rather than traditional views of truth taken from logic. As a consequence people are led to make apparently inconsistent or fallacious judgments. 


\section{Intensional reasoning}

Over the last thirty years, a common theme in research on adult conceptual reasoning has been the demonstration of effects of what Tversky and Kahneman (1983) called intuitive as opposed to extensional reasoning. The principle characteristic of this form of reasoning is that it is based on the intensional contents of conceptual representations, rather than the logical relations of sets in the actual world. "Intensional" and "extensional" are used here to distinguish two ways of individuating concepts at the level of individual concept possessors. The intensional content concerns the representation of the concept in the mind, through knowledge of the features and properties associated with it, whereas the extensional content of a concept concerns the set of things in the world that a person would consider as falling under the concept term. Both are to be understood in a psychological sense (as reflecting a person's set of beliefs) rather than a semantic sense (as reflecting the contribution of a word's meaning to the truth conditions of propositions expressed by statements or utterances). The contrast between this form of intuitive reasoning and the more rigourous (and valid) forms of logical reasoning has much in common with the Dual Systems model of reasoning in psychology (Evans, 2003 ; Sloman, 2002).

An early demonstration of intuitive or intensional reasoning was a study of the transitivity of category statements (Hampton, 1982). Based on earlier work in folk taxonomy (Kempton, 1978; Randall, 1976) the study provided participants with a set of category statements to be judged as true or false. While property statements have always been understood as generic (birds fly, fruit grows on trees) and expressing general rather than universal truth, category statements had been thought to convey a different kind of information. Being of a given kind carries with it an assumption of universal quantification - if a poodle is a kind of dog, then all poodles must be dogs. This idea that categorisation carries additional epistemological weight is supported by category learning and inference experiments where category and property information are treated differently (e.g. Yamauchi \& Yu, 2008), and in the developmental literature by studies showing that children consider a category statement to carry greater inductive potential (Gelman \& Heyman, 1999). For example (1) appears to say more about a person's fundamental nature than (2)

(1) he is a carrot-eater

(2) he eats a lot of carrots.

Statements in Study 1 in Hampton (1982) related to three levels of a concept hierarchy. Furniture was taken as the top level of a three layer hierarchy. The middle layer was exemplified by two typical basic level types of furniture (Bed and Chair), two atypical basic level types (Lamp and Shelf), and a related 
concept (Case). For each of these types, 16 items were created for the lowest level of the hierarchy that shared the common function of the set. For example for Bed they were all things to lie on, for Lamp they were all sources of light. Participants judged the items as members of the basic level type (e.g. Chair), and as members of the superordinate (Furniture), and also judged whether the basic level type was a member of the superordinate. Analysis focused on individual patterns of responding to the three elements in a transitive chain - $\mathrm{A}$ is a $\mathrm{B}, \mathrm{B}$ is a $\mathrm{C}$, and $\mathrm{A}$ is a $\mathrm{C}$. If the response to the first two was positive, but to the last was negative, then the pattern showed intransitivity.

Remarkably, some $25 \%$ of responses were of this kind, and they were as frequent in the typical subsets of Chair and Bed as in the atypical subsets. For example a majority of participants said that chair-lifts, sedan chairs and car seats were chairs but were not furniture, even though they agreed that chairs were very typical furniture. Looking at the examples of intransitivity it is clear that when people agree to a statement of the kind " $A$ is a type of $B$ ", or "As are $B s$ ", they do not intend this to imply that the set of As is fully included within the set of Bs. This point was made clear in the second study in Hampton (1982). The key issue concerned why people say that "chairs are furniture" even when they acknowledge that there are counterexamples. In the second study, these statements were presented twice, once at the start of the experiment, and then again at the end, after participants had experienced the counterexamples. There was no evidence for any reduction in the confidence with which people asserted the truth of these statements as a consequence of processing counterexamples. Chairs are considered good examples of furniture regardless of the existence of sedans or chair-lifts.

How does intensional reasoning account for this result? It appears that a categorical statement such as "chairs are furniture" is understood as a generic statement in just the same way as a property attribution such as "birds fly". They both reflect important and useful facts to know about chairs or birds, which help a person to operate with the concept in an efficient way. According to the Prototype Model of concepts (Hampton, 2007), chairs are considered to be furniture because the generic information stored with the chair concept has enough overlap or similarity with that stored with furniture to pass some threshold or criterion. Chairs are often made of wood, have legs and so forth (see Table 1), so they have enough features of furniture to count as furniture. Note how this way of categorizing the world depends only on the intensional properties of concepts, and makes no direct reference to the sets of such objects in the world. That is the reason that other objects, like car-seats, could have enough in common with chairs to count as chairs (sat upon and with back and seat), but not enough in common with furniture to count as furniture.

The fact that category statements can suffer counterexamples was further demonstrated in a set of studies on the conjunction, disjunction and 
negation of concepts (see Hampton, 1997, 2011 for reviews). For example in Hampton, 1988b, people were asked to categorize a list of words three times. First, for example, people judged whether the words named Sports, then whether they named Games, and finally whether they named Sports that are also Games. Extensional reasoning would require that people decide on the final classification by taking the two individual categorizations and using a simple conjunctive rule. An item is in the category "Sports that are also Games" only if it is both a sport and a game. For disjunction and negation, similar experiments were run looking at the relation of individual categorization in a pair of categories to categorization in complex phrases such as "Hobbies or Games" for disjunction, of "Sports that are not Games" for negation.

In all three kinds of conceptual combination, there was a systematic deviation from the predictions of extensional reasoning. One could expect that, given the vagueness of the category terms, people might give inconsistent responses. However the data showed strong and significant deviations from the expected logical pattern over and above what could be accounted for by randomness in the judgments.

To take conjunctions first, Chess, for example, was not considered a sport, but because it was such a clear example of a game, it was judged to belong to the conjunctive category "Sports that are also Games". Across many items and category combinations, overextension (including items in a conjunction that were excluded from one of the conjuncts) was much more common than the reverse pattern. A further study by Storms, Ruts, and Vandenbroucke (1998) confirmed that this overextension of the conjunction category is not peculiar to the restrictive relative clause form, but is also found in adjective-noun ("Deadly Diseases") or noun-noun ("Sea Fish") forms of modified noun phrases. The effect has been found both when individuals make all three judgments or when different groups are assigned to each judgment, and when people rate category membership on a scale, or when they simply make yes/no judgments (see Hampton, 2011, for details).

In the case of disjunctive combinations, overextensions were also seen. For example Mushrooms were considered poor examples of Vegetables, and were never called Fruit, but they had high rated membership in the disjunction "Fruit or Vegetables". Other cases showed significant underextension, with an item being less likely to be in the disjunctive set than in one of the disjuncts (see Hampton, 1988a for details). Finally, negating the relative clause as in "Sports that are not Games" led to even more extreme violations of the rules of set logic.

Explanation of these effects once more relies on the notion of intensional reasoning. Hampton (1987) showed how a conjunctive concept such as "Sports that are also Games" is also associated with an intensional set of generic properties. These activities are commonly physical, competitive, 
requiring skill and apparatus, have rules and teams, and so forth. This intension is itself derived from the intensions of the two conjuncts through a process of conceptual combination, that admits of a variety of additional effects designed to improve the coherence of the conjunctive concept, including the elimination of some properties and the importing of others. Overextension can arise because a particular exemplar may have more in common with the resulting new composite prototype concept than it does with one of the original conjunct concepts. For example "Pet Fish" are cared for like pets, and live in water like fish, but are not warm and cuddly, unlike other pets, and are not eaten with lemon, unlike other fish. The guppy or goldfish is therefore more similar to the conjunctive concept than it is to either of the conjuncts.

Briefly summarizing a series of studies, the conclusion can be drawn that category statements are indeed often generic, and that belief in their truth survives counterexamples. In the case of conjunction it seems that even the transparently true statement "Sports that are also games are sports" can have counterexamples, with chess being in the conjunction but not in the conjunct.

\section{The modifier effect in generics}

A more recent series of studies, conducted with Martin Jönsson, has looked at another interesting aspect of generic sentences. Following a study by Connolly et al. (2007) we investigated a phenomenon that we dubbed the modifier effect. Connolly et al. were concerned with the compositionality of conceptual combination, and argued that prototypes do not combine compositionally, which therefore rules them out as candidates for being concepts (see Fodor, 1998). As support for their argument they showed how the application of a modifier to the subject noun of a generic sentence has a general tendency to reduce the rated likelihood that the sentence is true. For example (3) was judged less true than (4).

(3) Lithuanian strawberries have seeds.

(4) Strawberries have seeds.

The effect was more pronounced when the modifier was atypical or unfamiliar in combination with the noun, as in this case. However it was also seen with a typical modifier, such as in (5).

(5) Red strawberries have seeds.

This paper has led to an interesting debate on the issue of prototypes and compositionality (Gleitman et al., 2012; Hampton \& Jönsson, 2012 ; Jönsson \& Hampton, 2008 ; 2012). For the present purpose, the effect is of interest because it provides a further chance to test whether categorical statements are in fact categorical or just generic. 
Both parties to the debate agree that the modifier probably reduces statement likelihood because it changes the prototype that is associated with the subject noun concept. Adding in additional features (such as being Lithuanian) to the prototype has the effect of reducing confidence in the value of other associated features. Thus being susceptible to the modifier effect should be an index of a generic sentence. As the conceptual content changes, so the relevance or importance of properties situated within that content become reduced.

Hampton, Passanisi \& Jönsson (2011) investigated whether this modifier effect would be more pronounced for generic properties that were mutable, rather than necessary or categorical. A mutable property is one that one can easily imagine being different, without serious consequences for the concept itself, regardless of whether it is universally true or not. For example there is a possible world in which swans are pink rather than white, but otherwise everything about them is the same. The whiteness of swans is therefore a mutable property. The same is not true of other properties. In a possible world where swans had no heart, or where swans were not birds, there would have to be some parallel shifts in the concepts of just what a swan (and/or a bird) actually is. Removing the heart from a swan would require adjustments to the biological theory of how swans function that would lead to other important changes in their make-up and properties. In the even more radical case that swans were not birds, either they would have to be changed so as not to have feathers, two legs, beaks and wings, and so forth, or the naïve theory of biological kinds itself would have to undergo major reorganization (as has happened at various stages in the history of biological classification). We hypothesized therefore that generic statements about mutable properties would show stronger effects of a modifier than generic statements about necessary or categorical features.

Surprisingly, it proved very hard to show any differential effect of the modifier on sentences of different mutability. Four studies were run comparing either central or categorical statements with mutable statements, and in every case the modifier reduced the likelihood of all statements to exactly the same degree. The effect was strangely insensitive to whether the statements were about easily changed mutable properties like (6), central properties like (7) or categorical properties like (8). In fact the conclusion reached by Hampton et al. (2011) was that the modifier effect is probably largely driven by pragmatic considerations. Thus they showed that when a brief textual context was provided prior to the judgments, establishing the bona fides of the modified concept, then only the mutable statements were affected by the modifier.

(6) Striped catfish have whiskers

(7) Striped catfish have bones 
(8) Striped catfish are fish

Leslie, Khemlani and Glucksberg (2011) have shown that generics are often considered true, even when universally quantified, an effect they call the Generic Overgeneralization Effect. Our data on the modifier effect also support this result. Jönsson \& Hampton (2006) investigated how modifiers would affect the judged likelihood of universally quantified generic sentences, such as (9) as opposed to (10).

(9) All sofas have backrests.

(10) All uncomfortable handmade sofas have backrests.

If the statements are taken as genuinely reflecting a universal truth, then there should be no reduction in likelihood when the modifier is added. If all sofas do in fact have backrests, then that should be true of comfortable, uncomfortable, factory made and handmade sofas alike. As might be expected however, the results were that the presence of the modifier reduced rated likelihood, leading to what we termed the Inverse Conjunction Fallacy. For example people considered it more likely that all strawberries have seeds than that all Lithuanian strawberries have seeds. (We removed any items where in a separate test people expressed any doubt that the Lithuanian strawberry, for example, was not a strawberry).

There is a logical connection between the Inverse Conjunction Fallacy and the Conjunction Fallacy originally reported by Tversky and Kahneman (1983). While their fallacy concerns subjective probabilities of individuals belonging in conjunctions, our fallacy concerns subjective probabilities of properties being universally true in conjunctions. While their fallacy is extensional (relating to individuals), ours is intensional (relating to properties).

Once again we conducted an extensive set of studies before we were able to find conditions in which this robust effect could be made to disappear. Emphasizing the universal quantification using statements phrased as in (11) through (13) had no significant effect on the extent of the fallacy

(11) All sofas always have backrests.

(12) Every single sofa has a backrest.

(13) $100 \%$ of sofas have backrests.

Nor did placing the sentences side by side and asking participants to choose the more likely, as in (14).

(14) Which of the following is more likely to be true?
A. All sofas have backrests
B. All uncomfortable handmade sofas have backrests 
As Leslie et al. (2011) also reported, it is very hard to convince people of the unacceptability of applying universal quantifiers to generic statements that are subject to counterexamples.

An unpublished study by Hampton and Lan (2006) examined how the modifier effect was influenced by the presence or absence of a universal quantifier. Sentences could be either modified or not, and could also be either generic, or quantified with " $A l l$ ". Each statement occurred in only one condition for each participant, but each participant saw a random mixture of all four kinds of sentence. The presence of universal quantifiers for just half the sentences should therefore have given the manipulation some prominence, through contrast with the rest.

Figure 1 shows the results. For unquantified generic sentences we found the standard modifier effect, with likelihood falling from 7.5 to 5.6 on a scale from 1 to 10 . The effect of including the universal quantifier " $A l l$ " was two-fold. First, "All" sentences were judged less likely, consistent with an acknowledgement on the part of the participants that it is in fact more likely that something is true in general than that it is true in every case. Second, there was a reduction in the size of the modifier effect, from a shift of 1.9 on the scale to a shift of only 0.9 . The interaction was significant, confirming that the effect had been moderated by the addition of the universal quantifier. However the modifier effect was still present and highly significant for the "All" statements. People were still happy with the paradoxical belief that a property is more likely to be true of every member of a category than true of every member of a subset of that category.

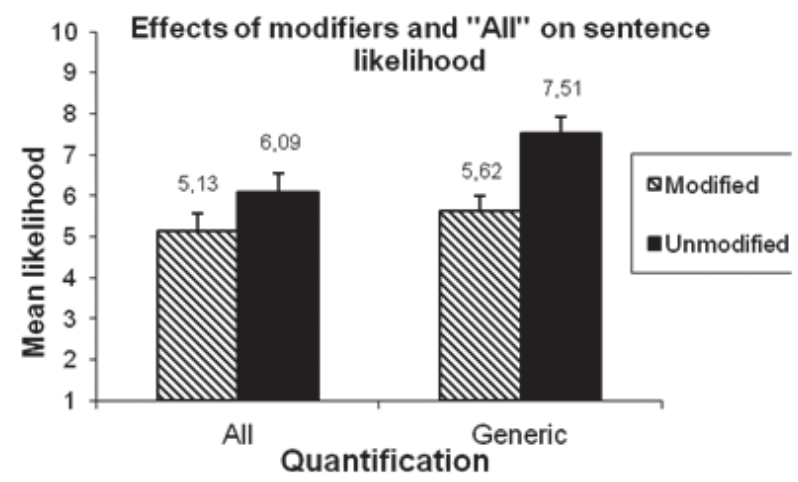

Figure 1: Results of the study by Hampton and Lan (2006) 


\section{Category-based induction}

There is related evidence in another area of cognitive science where categorical statements turn out to be treated more like generics. This is the case of category-based induction. In this task, people are asked to accept a premise stating that some property is true of all members of a given conceptual class, and are then asked to judge the likelihood that it is also true of all members of a related class. The property is usually some "blank" property about which people have no prior knowledge. In another version of the task, they may be asked to judge the strength of an argument such as (15).

All robins have property $\mathrm{P}$, therefore all sparrows have property $\mathrm{P}$.

The main finding in this task is that the more similar the two classes, then the more willing people are to generalise the property from the first to the second, or to accept the argument as strong.

In an extensive investigation of this form of reasoning, Osherson et al. (1990) described the Inclusion Fallacy. They asked people to compare the strength of two inductive arguments with universally quantified premises:

All Robins have property $\mathrm{P}$, therefore all Birds have property $\mathrm{P}$

All Robins have property P, therefore all Ostriches have property $\mathrm{P}$

Logically (if one may be forgiven for pointing this out to the reader), if the conclusion of (16) is true, and if one accepts that all ostriches are in fact birds, then the conclusion of (17) must also always be true. Consequently the second argument should not be rated as weaker than the first, which (of course) it was.

Sloman $(1993,1998)$ provided two further demonstrations of this type of fallacious reasoning. In his case, he showed that people differentiated the strength of two arguments that should both be considered perfectly valid. In the inclusion similarity effect, arguments such as (18) were preferred to those like (19):

All Birds have property P, therefore all Robins have property P.

All Birds have property P, therefore all Ostriches have property P.

In this case, the greater similarity of Birds to Robins than of Birds to Ostriches drives the feeling that the argument is stronger, even though everyone would acknowledge that both arguments should be perfectly valid. That is, no-one would fail to agree that all robins are birds, and that all ostriches are birds. The typicality of the subset lends strength to the argument, even when both subsets are included in the general category.

Correspondingly in Sloman's premise specificity effect, arguments such as (20) were preferred to those like (21): 
(20) All Apples have property P, therefore all McIntosh apples have property P.

(21) All Fruit have property P, therefore all McIntosh apples have property P.

Once again, similarity seems to be responsible for this effect. Both arguments are perfectly valid, given that they go from a property being true of a general class to its being true of a subset of that class. However the extra distance between Fruit and MacIntoshes renders the argument less compelling.

\section{Conclusions}

There is clearly a close correspondence between all the different phenomena described here. People are using similarity of intensional contents to drive judgments that should normatively depend only on extensional facts.

Jönsson and Hampton (2006) explained the situation as follows. As philosophy and logic students are quickly made aware, universally quantified statements can only strictly be verified by an exhaustive search for counterexamples and the failure to find them. "All swans are white" is notoriously much harder to prove true than to prove false. Human language has opted therefore to take a different approach to determining "truth" of such statements, one which frequently leads to judgments that appear fallacious from a logical perspective. Statements of this kind are judged true on the basis of the strength and importance of their association with the content of a concept. To say that "All S have property $P$ " in the context of everyday speech is to say something like "An important and relevant fact about the kind $S$ is that the property $P$ is to be found in individuals of that kind." As the Hampton and Lan (2006) result showed above, adding a universal quantifier to a generic statement merely raises the threshold for judging it to be true, but does not necessarily trigger people into extensional reasoning such as launching a search for counterexamples.

Naturally, this formulation of genericity raises the question of what makes a property important and relevant so that it becomes included in conceptual contents. Some answers to this question are to be found in recent research by Khemlani, Leslie, Glucksberg, Prasada and others (see for example, Prasada \& Dillingham, 2009). Having high frequency in the class, being causally linked to the kind's essential properties, and having important consequences for people are all candidate reasons for representing a property as generically true of a class. The research reviewed in this paper suggests that categorical statements are just as likely to be treated as generics as are property statements. 


\section{REFERENCES}

Connolly, Andrew; Fodor, Jerry; Gleitman, Lila; Gleitman, Henry (2007). Why stereotypes don't even make good defaults. Cognition 103: 1-22.

De Deyne, Simon; Verheyen, Stephen; Ameel, Eef; Vanpaemel, Wolf; Dry, Matt; Voorspoels, Wouter; et al. (2008). Exemplar by feature applicability matrices and other Dutch normative data for semantic concepts. Behavior Research Methods 40: 1030-1048.

Evans, Jonathan (2003). In two minds: Dual process accounts of reasoning. Trends in Cognitive Science 7: 454-459.

Fodor, Jerry (1998). Concepts: Where Cognitive Science Went Wrong. Oxford: Clarendon Press.

Gelman, Susan; Heyman, Gail (1999). Carrot-eaters and creature-believers: The effects of lexicalization on children's inferences about social categories. Psychological Science 10: 489-493.

Gleitman, Lila; Connolly, Andrew; Armstrong, Sharon (2012). Can prototype representations support composition and decomposition? In Werning, M.; Hinzen, W. \& Machery, E. (eds.) Oxford Handbook of Compositionality: 418-436. Oxford: Oxford University Press.

Hampton, James A. (1979). Polymorphous concepts in semantic memory. Journal of Verbal Learning and Verbal Behavior 18: 441-461.

HAMPTON, James A. (1982). A demonstration of intransitivity in natural categories. Cognition 12: 151-164.

Hampton, James A. (1987). Inheritance of attributes in natural concept conjunctions. Memory \& Cognition 15: 55-71.

Hampton, James A. (1988a). Disjunction of natural concepts. Memory \& Cognition 16: 579591.

Hampton, James A. (1988b). Overextension of conjunctive concepts: Evidence for a unitary model of concept typicality and class inclusion. Journal of Experimental Psychology: Learning, Memory and Cognition 14: 12-32.

Hampton, James A. (1997). Conceptual combination. In Lamberts, K. \& Shanks, D.R. (eds.) Knowledge, Concepts and Categories: 135-162. Hove: Psychology Press.

Hampton, James A. (2007). Typicality, graded membership and vagueness. Cognitive Science 31: 355-383.

Hampton, James A. (2011). Conceptual combinations and fuzzy logic. In Belohlavek, R. \& Klir, G. J. (eds.) Concepts and Fuzzy Logic: 209-231. Cambridge: MIT Press.

HAMPTON, James A.; JönssOn, Martin L. (2012). Typicality and compositionality: The logic of combining vague concepts. In Werning, M.; Hinzen, W. \& Machery, E. (eds.) Oxford Handbook of Compositionality: 385-402. Oxford: Oxford University Press.

HAMPTON, James, A.; LAN, Ou (2006). Quantification and the modifier effect. Unpublished MS. City University London.

Hampton, James A.; PAssanisi, Alessia; Jönsson, Martin L. (2011). The modifier effect and property mutability. Journal of Memory and Language 64: 233-248.

Jönsson, Martin L.; HAMPTON, James A. (2006). The inverse conjunction fallacy. Journal of Memory and Language 55: 317-334.

Jönsson, Martin L.; Hampton, James A. (2008). On prototypes as defaults (Comment on Connolly, Fodor, Gleitman and Gleitman, 2006). Cognition 106: 913-923. 
Jönsson, Martin L.; Hampton, James A. (2012). The modifier effect in within-category induction: Default inheritance in complex noun phrases. Language and Cognitive Processes 27: 90-116.

Kempton, Willett (1978). Category grading and taxonomic relations: A mug is a sort of cup. American Ethnologist 5: 44-65.

LAKOFF, George (1973). Hedges: A study in meaning criteria and the logic of fuzzy concepts. Journal of Philosophical Logic 2: 458-508.

Leslie, Sarah-Jane; Khemlani, Sangeet; Glucksberg, Sam (2011). Do all ducks lay eggs? The generic overgeneralization effect. Journal of Memory and Language 65: 15-31.

McRae, Ken; Cree, George; Seidenberg, Mark; McNorgan, Chris (2005). Semantic feature production norms for a large set of living and nonliving things. Behavior Research Methods, Instruments, \& Computers 37: 547-559.

Osherson, Daniel; Smith, Edward; Wilkie, Ormond; Lopez, Alejandro (1990). Categorybased induction. Psychological Review 97: 185-200.

Prasada, Sandeep; Dillingham, Elaine (2009). Representation of principled connections: A window onto the formal aspect of common sense conception. Cognitive Science 33: 401-448.

Randall, Robert (1976). How tall is a taxonomic tree? Some evidence for dwarfism. American Ethnologist 3: 543-553.

Rosch, Eleanor (1975). Cognitive representations of semantic categories. Journal of Experimental Psychology: General 104: 192-232.

Sloman, Steven (1993). Feature-based induction. Cognitive Psychology 25: 231-280.

Sloman, Steven (1998). Categorical inference is not a tree: The myth of inheritance hierarchies. Cognitive Psychology 35: 1-33.

Sloman, Steven (2002). Two systems of reasoning. In Gilovich T; Griffin D \& Kahneman D (eds.) Heuristics and biases: The psychology of intuitive judgment: 379-398. Cambridge: Cambridge University Press.

Storms, Gert; Ruts, Wim; Vandenbroucke, Anneloes (1998). Dominance, overextensions, and the conjunction effect in different syntactic phrasings of concept conjunctions. European Journal of Cognitive Psychology 10: 337-372.

Tversky, Amos; Kahneman, Daniel (1983). Extensional versus intuitive reasoning: The conjunction fallacy in probability judgment. Psychological Review 90: 293-315.

Wu, Ling-Ling; Barsalou, Lawrence (2009). Perceptual simulation in conceptual combination: Evidence from property generation. Acta Psychologica 132: 173-189.

YamauchI, Takashi; Yu, Na-Yung (2008). Category labels versus feature labels: Category labels polarize inferential predictions. Memory \& Cognition 36: 544-553. 


\section{RÉSUMÉ}

Nous proposons que les génériques reflètent la nature du système conceptuel, qui, par ses structures prototypiques et ses frontières vagues, déstabilise les traitements logiques traditionnels. Les représentations conceptuelles contiennent les informations que l'on considère pertinentes et appropriées pour comprendre et se familiariser avec le concept en question. Ces informations incluent des traits fondamentaux et ontologiques, ainsi que des informations sur la forme ordinaire ou typique que peuvent prendre les exemplaires du concept, et tout autre information qu'il est important de connaître. Nous utilisons des exemples de la littérature de psychologie pour illustrer la relation qui existe entre les génériques et les erreurs de raisonnement qui peuvent se produire à cause de la dépendance des concepts liés à la notion de similitude. Afin de comprendre la logique des génériques, nous devrions donc nous intéresser aux processus par lesquels les information s'attachent et s'intègrent à la représentation d'un concept.

\section{Mots-CléS}

Génériques, concept, prototype, similarité, raisonnement. 
